\title{
Cervical Ripening With Prostaglandin Gel and Hygroscopic Dilators
}

\author{
J.U. Hibbard,* A. Shashoua, C. Adamczyk, and M. Ismail \\ Department of Obstetrics and Gynecology, University of Chicago, Chicago, IL
}

\begin{abstract}
Objective: To study the effectiveness and morbidity of adding hygroscopic cervical dilators to prostaglandin gel for cervical ripening and labor induction.

Study design: Patients of at least 34 weeks' gestation with a medical indication for induction of labor and with a modified Bishop score of 5 or less were randomized to receive either prostaglandin gel or prostaglandin gel with hygroscopic cervical dilators. Primary outcomes were time to delivery, change in cervical score, and infection. Secondary outcomes included cesarean delivery rate and deliveries before 24 hours of induction. Continuous variables were analyzed by Wilcoxon sum rank test and categorical data by chi-square or Fisher exact test, with $P<0.05$ being significant.

Results: Seventeen patients were randomized to intracervical prostaglandin alone and 23 patients received intracervical prostaglandin plus hygroscopic dilators. No demographic differences were noted between the groups. After six hours of ripening, the combined group achieved a greater change in Bishop score (3.6 vs. $2.1, P=0.007)$ and tended to have a shorter induction time $(21.7 \mathrm{vs}$. 26.4 hours, $P=0.085$ ). The combined therapy group had a higher infection rate than the prostaglandin-only group $(59 \%$ vs. $12 \%, P=0.003)$.

Conclusion: Combining cervical dilators with prostaglandin gel provides more effective cervical ripening and a more rapid induction to delivery interval than prostaglandin alone but with a significant and prohibitive rate of infection. Infect. Dis. Obstet. Gynecol. 6:18-24, 1998.

(c) 1998 Wiley-Liss, Inc.
\end{abstract}

KEY WORDS

infectious morbidity; cervical ripening; induction of labor; prostaglandin laminaria

L

abor induction is common in modern obstetrics, with attention rightly directed toward the development of effective cervical ripening and induction techniques. Prostaglandin gel, intracervical mechanical devices, oral mifepristone, vaginal misoprostol, and extraamniotic saline infusions are some of the agents investigated in recent years. ${ }^{1-6}$ The safety and efficacy of single-agent therapy with prostaglandin $\mathrm{E}_{2}\left(\mathrm{PGE}_{2}\right)$ gel for preinduction ripening of the cervix has been well documented. ${ }^{4-9}$ PGE $_{2}$ stimulates a change in the molecular structure of the cervix and can also cause uterine contractions. ${ }^{9}$ There has been no documented increased risk of intrauterine infection with the use of this agent either intracervically or intravaginally. Hygroscopic cervical dilators have also been investigated as a single-agent method of preinduction cervical ripening. ${ }^{6,10-11}$ These dilators absorb moisture through hygroscopic action, drawing fluid from the cervical stroma, resulting in softening of the tissue. As the dilators absorb fluid, axial expansion causes mechanical dilation of the cervix, as well as local production of endogenous prostaglandin that may contribute to their mechanism of action. ${ }^{10-11}$ Findings on whether mechanical dilators promote an increase in intrauterine infection have not been consistent. ${ }^{6,10-12}$

In an attempt to shorten the time from induc-

*Correspondence to: Dr. Judith U. Hibbard, Department of Obstetrics and Gynecology, University of Chicago, 5841 South Maryland Avenue, MC 2050, Chicago, IL 60637. E-mail: jhibbard@babies.bsd.uchicago.edu 
TABLE I. Modified Bishop scoring ${ }^{a}$

\begin{tabular}{lccc}
\hline & \multicolumn{3}{c}{ Score } \\
\hline Dilation & 0 & I & 2 \\
Effacement & $<0.5 \mathrm{~cm}$ & $0.5-1.5 \mathrm{~cm}$ & $>1.5 \mathrm{~cm}$ \\
Station & 0 & $\leq 50 \%$ & $>50 \%$ \\
Cervical consistency & -3 & $-2 /-1$ & 0 \\
Cervical position & Posterior & Medium & Soft \\
\hline
\end{tabular}

ajagani N, Schulman H, Fleischer A: Role of the cervix in induction of labor. Obstet Gynecol 59: 21-25, 1982.

tion to delivery, a number of clinicians at our institution began combining the use of Dilapan ${ }^{\circledR}$ hygroscopic dilators (Gynotech, Middlesex, NJ) with Prepidil Gel ${ }^{\circledR}$, the commercially available intracervical $\mathrm{PGE}_{2}$ preparation (Upjohn, Kalamazoo, $\mathrm{MI}$ ). Because of our concern regarding the efficacy and safety of this approach, we undertook this randomized, controlled trial to compare prostaglandin gel used in combination with hygroscopic dilators to prostaglandin gel alone for cervical ripening.

\section{MATERIALS AND METHODS}

This study was performed at the University of Chicago, Chicago Lying-in Hospital, between August 1, 1994, and May 1,1995, and all patients admitted for induction of labor were invited to participate. Inclusion criteria were gestational age of at least 34 weeks, a medical or obstetric indication for induction of labor, a modified Bishop score of 5 or less (Table 1), ${ }^{13}$ cervical dilation less than $1 \mathrm{~cm}$, vertex presentation, and intact membranes. Those excluded from participation were patients with previous cesarean delivery for cephalopelvic disproportion, severe asthma, overt cervicitis, nonreassuring fetal testing, fetal macrosomia, multiple gestation, and those with any contraindication to vaginal delivery. The University of Chicago group B streptococcus screening policy at that time included universal rectovaginal cultures for group B streptococcus at 29 weeks of gestation, with antibiotic treatment for all those with positive cultures in labor. Patients were randomized to treatment using a computer-generated randomization chart, and assignments were contained within sequential opaque envelopes kept in the labor and delivery suites. Informed written consent was obtained from all enrolled patients. The study was approved by the University of Chicago Institutional Review Board.

Patients randomized to prostaglandin only re- ceived an initial dose of $0.5 \mathrm{mg}$ of Prepidil Gel ${ }^{\circledR}$ (Upjohn, Kalamazoo, MI) using the following technique for administration. During a sterile speculum examination, the Prepidil $\mathrm{Gel}^{\circledR}$ was instilled into the cervix at the level of the internal os, according to the packaging instructions. The patient then remained in the labor and delivery area for continuous fetal heart and tocodynamic monitoring. Reexamination of the cervix occurred after six hours, at which time a second dose of $0.5 \mathrm{mg}$ of Prepidil $\mathrm{Gel}^{\circledR}$ was administered in the same fashion.

Patients randomized to the combined therapy group also underwent sterile speculum examination, and the cervix and upper vagina were cleansed with povidone-iodine. The anterior lip of the cervix was stabilized with sterile ring forceps, and a single dose of $0.5 \mathrm{mg}$ of Prepidil Gel ${ }^{\circledR}$ was placed intracervically as previously described. Using gentle traction on the cervix, a Dilapan ${ }^{\circledR}$ hygroscopic dilator (Gynotech, Middlesex, NJ), measuring $4 \times 55 \mathrm{~mm}$, was inserted into the cervical canal to the level of the internal os or until its hub was flush with the external os. Additional dilators were placed at that time until no more could be readily inserted, usually between three and seven. The upper vagina was then packed with sterile gauze to assure the position of the dilators. After 6 hours of continuous fetal and tocodynamic monitoring, the Dilapan ${ }^{\circledR}$ were removed, the cervix reassessed, and a second dose of $0.5 \mathrm{mg}$ Prepidil ${ }^{\circledR}$ administered.

After the 12 hour preinduction study phase, routine obstetric care was instituted as usual. This might include use of a third dose of Prepidil Gel ${ }^{\circledR}$ if the Bishop score was less than 5, initiation of oxytocin, and amniotomy. Decisions regarding the use of labor analgesia and the option of cesarean delivery were left to the discretion of the managing team in the labor and delivery section. None of the enrolled patients received antibiotic therapy before enrollment in the study.

Chorioamnionitis was diagnosed by an intrapartum temperature greater than $38.0^{\circ} \mathrm{C}$ in the absence of any other identifiable cause for fever and any of the following factors: fetal tachycardia, fundal tenderness, or foul-smelling amniotic fluid. Endomyometritis was defined as a temperature of greater than $38.4^{\circ} \mathrm{C}$ within the first 24 hours following delivery or greater than $38.0^{\circ} \mathrm{C}$ after 24 hours postpartum, in addition to one of the follow- 
TABLE 2. Patient demographics ${ }^{\mathrm{a}}$

\begin{tabular}{|c|c|c|c|}
\hline & $\begin{array}{c}\text { Dilapan }^{\circledR} \text { and Prepidil }{ }^{\circledR} \\
(\mathrm{n}=22)\end{array}$ & $\begin{array}{l}\text { Prepidil }^{\circledR} \text { only } \\
(\mathrm{n}=17)\end{array}$ & $P$-value \\
\hline Age (years) & $22.9 \pm 5.2$ & $23.6 \pm 7.1$ & NS \\
\hline \multicolumn{4}{|l|}{ Race: } \\
\hline African American & $19(86.4 \%)$ & $16(94.1 \%)$ & NS \\
\hline White & $3(13.6 \%)$ & I (5.9\%) & NS \\
\hline \multicolumn{4}{|l|}{ Parity } \\
\hline 0 & $13(59.1 \%)$ & $9(52.9 \%)$ & NS \\
\hline$\geq 1$ & $9(40.9 \%)$ & $8(47.1 \%)$ & NS \\
\hline Mean & $.77 \pm 1.3$ & $1.24 \pm 1.7$ & NS \\
\hline \multicolumn{4}{|l|}{ Gestation age (weeks) } \\
\hline All & $38.8 \pm 2.2$ & $39.3 \pm 2.3$ & NS \\
\hline $34-36$ & $4(18.2 \%)$ & $4(23.5 \%)$ & NS \\
\hline$\geq 37$ & $18(81.8 \%)$ & $13(76.5 \%)$ & NS \\
\hline Bishop score at onset & $2.3 \pm 1.2$ & $2.8 \pm 1.5$ & NS \\
\hline Previous cesarean delivery & $4(18 \%)$ & I (5\%) & NS \\
\hline \multicolumn{4}{|l|}{ Anesthesia } \\
\hline Epidural & $19(86.4 \%)$ & $15(88.2 \%)$ & NS \\
\hline Other & $3(13.6 \%)$ & $2(11.8 \%)$ & NS \\
\hline
\end{tabular}

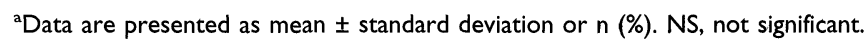

ing: uterine tenderness, elevated white blood cell count, or purulent vaginal discharge.

Primary outcome variables to be analyzed included hours from induction to delivery, change in modified Bishop score, and intrauterine infection. Also compared were cesarean delivery rate, labor onset during ripening, operative vaginal delivery, percent of patients delivered before 24 hours, uterine hypertonus, fetal heart rate abnormalities, Apgar scores, and cord blood $\mathrm{pH}$ values.

Using the induction-to-delivery interval as the outcome variable, a power calculation revealed that 136 patients were required for enrollment in order to demonstrate a 2-hour difference in induction-todelivery interval with $80 \%$ power and an alpha of 0.05 . Continuous variables were analyzed using the Wilcoxon sum rank test and categorical data were analyzed by Chi-square or the Fisher exact test, with $P<0.05$ considered to be statistically significant.

\section{RESULTS}

A total of 44 patients were enrolled in the study. Information was available for 43 patients. Four patients were randomized but excluded from the study prior to the administration of the study medications. Of the four, one patient was discovered to have severe asthma, one developed repetitive decelerations prior to induction, and two were noted (upon review of the medical records chart) to have undergone previous cesarean delivery for cephalopelvic disproportion. Of the remainder, 22 patients received combined therapy and 17 patients received prostaglandin alone. Enrollment ended prematurely in May 1995 when Gynotech removed Dilapan ${ }^{\circledR}$ from the United States market.

There were no significant differences between groups with respect to maternal age, race, parity, gestational age, or Bishop score at the start of induction (Table 2), as well as no difference in duration of rupture of membranes and intraprtum number of vaginal exams. Indications for induction of labor are listed in Table 3, the most common being hypertensive disorders and past-due dates, an acceptable indication at our institution, where many patients undergo induction of labor when their gestations extend beyond 41 weeks.

Delivery outcomes are displayed in Table 4. The overall cesarean delivery rate was $25.6 \%$, while the operative vaginal delivery rate was $20.5 \%$. There was a trend toward a higher cesarean delivery rate in the Dilapan ${ }^{\circledR}$ plus Prepidil ${ }^{\circledR}$ group (36.4\%) compared with the Prepidil ${ }^{\circledR}$ only group (11.8\%), though this did not reach statistical significance $(P=0.083)$. There were no significant differences in birth weights, five-minute Apgar scores less than 5, or cord $\mathrm{pH}$ values less than 7.20.

The combined Dilapan ${ }^{\circledR}$ and Prepidil ${ }^{\circledR}$ group achieved a greater change in modified Bishop score in the first 6 hours of induction when compared 
TABLE 3. Indication for labor induction

\begin{tabular}{lcc}
\hline & $\begin{array}{c}\text { Dilapan }{ }^{\circledR} \text { and } \\
\text { Prepidil }^{\circledR} \\
(\mathrm{n}=22)\end{array}$ & $\begin{array}{c}\text { Prepidil }^{\circledR} \text { only } \\
(\mathrm{n}=17)\end{array}$ \\
\hline Past-dates (>4I weeks) & 6 & 6 \\
Diabetes & 3 & 1 \\
Hypertension and & 10 & 6 \\
preeclampsia & & 1 \\
Orowth retardation & 1 & 1 \\
History of fetal demise & 1 & 1 \\
Fetal tachyarrhythmia & 0 & 0 \\
Rh isoimmunization & 1 & 1 \\
\hline
\end{tabular}

with the Prepidil ${ }^{\circledR}$ group $(3.63 \pm 1.8$ vs. $2.05 \pm 1.3$, $P=0.0074$, Table 5 . Of those patients who were delivered vaginally, there was a shorter induction to delivery interval noted in the combined group $\left(21.7 \pm 6.2\right.$ hours) compared with the Prepidil ${ }^{\circledR}$ alone group (26.4 \pm 9.6 hours); however, this trend did not reach statistical significance $(P=0.0847$, Table 5). A greater percentage of patients were delivered by 24 hours in the combined group as compared with the prostaglandin only group ( $40.9 \%$ vs. $29.4 \%, P=0.097$, Table 5 ). There was no difference in the need for a third dose of Prepi$\mathrm{dil}^{\circledR}$ or the number of patients reaching active labor in 12 hours. In our study group, patients with endometritis and chorioamnionitis cultures showed organisms of the aerobic gram-negative bacilli group, mainly Escherichia coli, as well as anaerobic gram-negative bacilli, as well as aerobic grampositive cocci, mainly Streptococcus agalactiae.

Table 6 shows the differences in maternal infectious morbidity between the two groups. Chorioamnionitis or endometritis occurred in $59 \%$ of patients who received Dilapan ${ }^{\circledR}$ and Prepidil ${ }^{\circledR}$, compared with $12 \%$ of patients in the single-agent Prepidil ${ }^{\circledR}$ only group. When stratified by mode of delivery, the difference remained statistically significant for those who delivered vaginally $(50 \%$ vs. $6.7 \%, P=0.0126)$. The rate of infection among those in the combined treatment group who had cesarean deliveries was not different from those who received prostaglandin alone ( $75 \%$ vs. $50 \%)$, but the number of patients in this category was very small.

Five patients in the combined group had cesarean deliveries for failure to progress, all at greater than $4 \mathrm{~cm}$ of cervical dilation, compared with two patients in the prostaglandin-only group. The re- maining three cesarean deliveries in the combined group were performed for fetal distress occurring remote from delivery, as well as remote from the study treatments. There were no instances of postpartum hemorrhage, uterine hypertonus, uterine rupture, or neonatal death.

\section{DISCUSSION}

In this prospective, randomized, controlled trial, we were able to demonstrate that combining hygroscopic dilators with intracervical prostaglandin gel led to a greater change in cervical exam, as compared with prostaglandin gel alone. This difference between the two groups of patients persisted at 12 hours and may have led to the overall shorter induction-to-delivery interval observed in the combined therapy group, though these results did not reach statistical significance. The percentage of patients reaching active labor in the first 12 hours of treatment and the number delivered by 24 hours was also greater in the combined treatment group. The observed difference in cervical scores was not at the expense of fetal well-being, as evidenced by similar Apgar scores, umbilical cord blood gases, incidences of fetal distress, and heart rate decelerations.

We were unable to locate any previous investigations that evaluate the combination of mechanical methods with prostaglandin gel for cervical ripening. A recent randomized comparison by Sanchez-Ramos et al. $^{6}$ of the efficacy of hygroscopic cervical dilators versus prostaglandin gel noted no significant difference in change in Bishop score, amniotomy-to-delivery time, and maximum dose of oxytocin. A comparison of a synthetic polyvinyl sponge dilator containing magnesium sulfate (Lamicel ${ }^{\circledR}$ ) to $\mathrm{PGE}_{2}$ vaginal gel found the agents to be equally effective. ${ }^{14}$ Keirse, in a systematic review of well-performed investigations regarding cervical ripening, indicates that prostaglandin administration is more likely to result in the onset of labor than is the insertion of mechanical devices. ${ }^{15}$ We did not include a Dilapan ${ }^{\circledR}$ only arm in the present investigation, so a direct comparison is not possible with this previous work. However, it may be that the significant difference we noted in cervical score achieved with combination therapy is related to a synergistic effect obtained by adding prostaglandin gel to the cervical dilators. 
TABLE 4. Delivery outcomes ${ }^{\mathrm{a}}$

\begin{tabular}{|c|c|c|c|c|}
\hline & $\begin{array}{c}\text { Dilapan }^{\circledR} \text { and Prepidi }{ }^{\circledR} \\
(n=22)\end{array}$ & $\begin{array}{l}\text { Prepidil }{ }^{\circledR} \text { only } \\
\quad(n=17)\end{array}$ & $P$-value & $\begin{array}{c}\text { Relative risk } \\
{[95 \% \text { confidence interval] }}\end{array}$ \\
\hline Vaginal delivery & $14(63.6 \%)$ & $15(88.2 \%)$ & NS & \\
\hline Operative vaginal delivery & $4(18.2 \%)$ & $4(23.5 \%)$ & NS & \\
\hline Cesarean delivery & $8(36.4 \%)$ & $2(11.8 \%)$ & 0.083 & $3.09[0.75-12.72]$ \\
\hline Birth weight $(g)$ & $3149 \pm 542$ & $3026 \pm 661$ & NS & \\
\hline 5-minute Apgar $<5$ & 0 & 0 & NS & \\
\hline Arterial umbilical cord $\mathrm{pH}<7.20$ & $4(18.2 \%)$ & $3(17.7 \%)$ & NS & \\
\hline
\end{tabular}

${ }^{a}$ Data are presented as mean \pm standard deviation or $n(\%)$. NS, not significant.

TABLE 5. Cervical ripening outcomes ${ }^{\mathrm{a}}$

\begin{tabular}{|c|c|c|c|}
\hline & $\begin{array}{c}\text { Dilapan }^{\circledR} \text { and Prepidil }{ }^{\circledR} \\
(n=22)\end{array}$ & $\begin{array}{l}\text { Prepidil }{ }^{\circledR} \text { only } \\
(n=17)\end{array}$ & $P$-value \\
\hline Change in Bishop score in first 6 hours & $3.6 \pm 1.8$ & $2.1 \pm 1.3$ & 0.0074 \\
\hline Induction-to-delivery interval (hours) & $21.7 \pm 6.2$ & $26.41 \pm 9.6$ & 0.0847 \\
\hline Delivered by 24 hours & $9(40.9 \%)$ & $5(29.4 \%)$ & 0.097 \\
\hline Third dose of Prepidil & $7(31.8 \%)$ & $7(41.2 \%)$ & 0.496 \\
\hline Active labor in 12 hours & $14(63.6 \%)$ & $8(47.1 \%)$ & 0.239 \\
\hline
\end{tabular}

${ }^{a}$ Data are presented as mean \pm standard deviation or $\mathrm{n}(\%)$.

TABLE 6. Maternal infection

\begin{tabular}{lcccc}
\hline & $\begin{array}{c}\text { Dilapan }{ }^{\circledR} \text { and Prepidil } \\
(\mathrm{n}=22)\end{array}$ & $\begin{array}{c}\text { Prepidil }{ }^{\circledR} \text { only } \\
(\mathrm{n}=17)\end{array}$ & $\begin{array}{c}\text { Relative risk } \\
\text { P-value }\end{array}$ & $\begin{array}{c}\text { [95\% confidence interval] } \\
{[95 \%}\end{array}$ \\
\hline All patients & $13(59 \%)$ & $2(12 \%)$ & 0.0029 & $5.02[1.31-19.33]$ \\
Vaginal & $7 / 14(50 \%)$ & $1 / 15(6.7 \%)$ & 0.0126 & $7.50[1.05-53.49]$ \\
Cesarean delivery & $6 / 8(75 \%)$ & $1 / 2(50 \%)$ & 0.533 & \\
\hline
\end{tabular}

The most concerning finding in our study is the high rate of intrauterine infection in the combined treatment group. Of those patients randomized to combined therapy, 59\% developed chorioamnionitis or endometritis, compared with only $12 \%$ in the single-agent prostaglandin group. Previous investigations of cervical ripening agents with regard to intrauterine infection are not in agreement. Sanchez-Ramos et al. ${ }^{6}$ noted the rate of chorioamnionitis and endometritis in an intracervical prostaglandin gel group to be identical to that in a Dilapan ${ }^{\circledR}$ group (15\% vs. $\left.16.6 \%\right)$. In a direct comparison of Dilapan ${ }^{\circledR}$ and laminaria, Blumenthal and Ramanauskas ${ }^{10}$ found no intrapartum pyrexia or infection in either group. Lin et al. ${ }^{12}$ compared laminaria with extraamniotic saline infusions and reported a $30.8 \%$ intrauterine infection rate in the laminaria group. Kazzi et al. ${ }^{11}$ noted a very high rate of intrauterine infection, $60 \%$, in a retrospective study in which laminaria tents were used for cervical ripening, compared with only $11 \%$ in the control group. Furthermore, five cases of neonatal sepsis occurred in the laminaria group, while none were noted in the control group. Interestingly, our maternal infectious morbidity rate in the combined dilator and prostaglandin group is almost identical to that of Kazzi et al.'s ${ }^{11}$ laminaria group.

In the current study the high infection rate was unexpected. Theoretically, manipulation of the cervix may increase the likelihood of bacterial ascension to the uterine cavity. Combining dilators with intracervical gel increases cervical manipulation, which may lead to higher infection rates. Overt cervicitis was an exclusion factor for this study. All patients were cultured at their first prenatal visit for Neisseria gonorrhoeae and Chlamydia trachomatis, and those with positive results were treated at that time. Clinical screening for group B streptococcus was performed at 28 weeks of gestation. Cervical cultures were not routinely obtained at the time of admission for labor induction. The high rate of intrauterine infection is important in that it may have an impact on clinical problems during labor, including a dysfunctional labor pat- 
tern and fetal stress. The presence of fever during labor necessitates the initiation of intravenous antibiotics for the gravida, usually continued after delivery and also for the neonate until sepsis has been ruled out. This management scheme not only increases the cost of care, but also lengthens the hospital stay for mother and newborn.

Women who begin labor with a more advanced cervical exam are known to have a shorter induction period and a greater chance for vaginal delivery compared with those with unripe cervices. ${ }^{1,13}$ For this reason, after noting better cervical ripening in the combined therapy group, we anticipated that this cohort might have had a lower cesarean delivery rate than the prostaglandin only group. However, we were surprised to note a trend toward a higher cesarean delivery rate in the combined therapy group. Again, the high incidence of maternal infectious morbidity may have contributed to the higher rate of operative deliveries. It is important to note that the high maternal infection rate in the combined therapy group persisted, even when considering only those patients delivering vaginally.

The current study ended abruptly in May 1995 when Dilapan ${ }^{\circledR}$ was removed from the United States market by Gynotech, resulting in our much smaller than anticipated sample size. While a significant difference in cervical scores and infection rates were noted, additional conclusions are limited. We realize that type II statistical errors may readily occur in this small study. We considered changing the protocol to continue the study with generic laminaria; however, differences in the efficacy of laminaria compared with Dilapan ${ }^{\circledR}$ may have prevented a meaningful comparison. ${ }^{10}$ The addition of a Dilapan ${ }^{\circledR}$ only arm would have improved our study design, but an even larger sample size would have been required. Bias in our study may have occurred because the physician determining the posttreatment cervical score was aware of the treatment arm to which each patient was randomized. A double-blinded study would eliminate this bias but would be difficult to conduct with the personnel available and the structure of the resident service in this large teaching hospital. Decisions regarding other important outcomes such as cesarean delivery and timing of delivery, however, involved management by a larger group of physicians, lessening the influence of individual bias.

\section{CONCLUSION}

Combining hygroscopic cervical dilators with prostaglandin gel leads to more effective cervical ripening and a potentially more rapid induction to delivery interval than administering prostaglandin alone. Unfortunately, these benefits are outweighed by a significant and prohibitively high rate of intrauterine infection. While awaiting a larger, more comprehensive evaluation of these methods, the clinician faces the dilemma of whether achieving a more rapid delivery is worth the risk of the maternal infectious morbidity noted in our prospective trial.

\section{REFERENCES}

1. American College of Obstetricians and Gynecologists: Induction and augmentation of labor. ACOG Technical Bulletin no. 157, Washington, DC, 1991.

2. Atad, J, Bornstein J, Calderon I, Petrikovsky BM, Sorokin Y, Bramovici $\mathrm{H}$ : Nonpharmaceutical ripening of the unfavorable cervix and induction of labor by a novel double balloon device. Obstet Gynecol 77:146-152, 1991.

3. Ramos LS, Kaunitz AM, DelValle G, et al.: Labor induction with the prostaglandin E1 methyl analogue Misoprostol versus oxytocin, a randomized trial. Obstet Gynecol 81:332-336, 1993.

4. Buchanan D, Macer J, Yonekura ML: Cervical ripening with prostaglandin E2 vaginal suppositories. Obstet Gynecol 63:659-663, 1984.

5. Buttino LT, Garite TJ: Intracervical prostaglandin in postdate pregnancy, a randomized trial. J Reprod Med 35:155-158, 1990.

6. Sanchez-Ramos L, Kaunitz AM, Connor PM: Hygroscopic cervical dilators and prostaglandin E2 gel for preinduction cervical ripening, a randomized prospective comparison. J Reprod Med 37:355-359, 1992.

7. Owen J, Winkler CL, Harris BA, Hauth JC, Smith MC: A randomized, double-blind trial of prostaglandin E2 gel for cervical ripening and meta-analysis. Am J Obstet Gynecol 165:991-996, 1991.

8. Trofatter KF: Effect of preinduction cervical softening with dinoprostone gel on outcome of oxytocin-induced labor. Clin Ther 15:838-844, 1993.

9. Laube DW, Zlatnik FJ, Pitkin RM: Preinduction cervical ripening with prostaglandin $\mathrm{E} 2$ intracervical gel. Obstet Gynecol 68:54-57, 1986.

10. Blumenthal, PD, Ramanauskas R: Randomized trial of Dilapan and laminaria as cervical ripening agents before induction of labor. Obstet Gynecol 75:365-368, 1990. 
11. Kazzi GM, Bottoms SF, Rosen MG: Efficacy and safety of laminaria digitata for preinduction ripening of the cervix. Obstet Gynecol 60:440-443, 1982.

12. Lin A, Kupferminc M, Dooley SL: A randomized trial of extra-amniotic saline infusion versus laminaria for cervical ripening. Obstet Gynecol 86:545-549, 1995.

13. Jagani N, Schulman H, Fleischer A: Role of the cervix in the induction of labor. Obstet Gynecol 59:21-25, 1982.
14. Johnson IR, Macpherson MBA, Welch CC, et al.: A comparison of Lamicel and prostaglandin $\mathrm{E} 2$ vaginal gel for cervical ripening before induction of labor. Am J Obstet Gynecol 151:604-607, 1985.

15. Keirse MJNC: Prostaglandins vs mechanical methods for cervical ripening. In: Pregnancy and Childbirth Module, Cochrane Database of Systematic Reviews: Review no. 03867, April, 1992. 


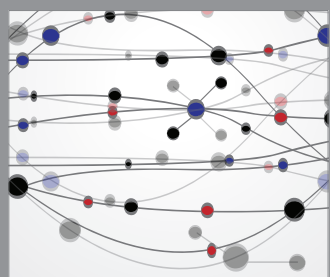

The Scientific World Journal
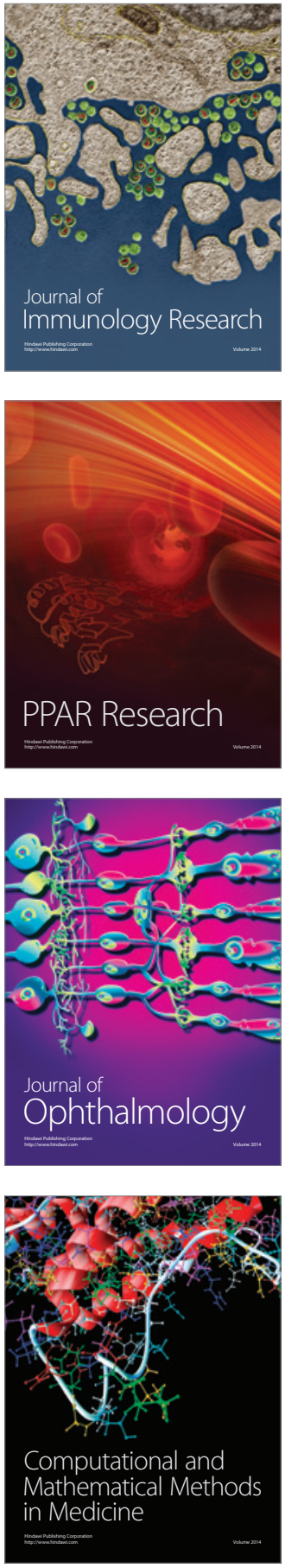

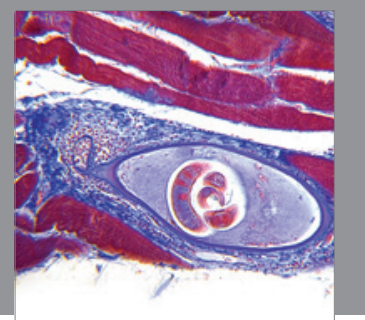

Gastroenterology

Research and Practice
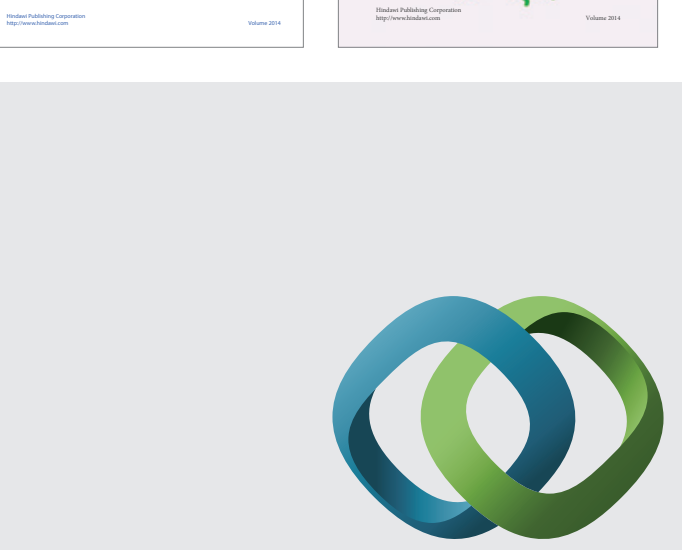

\section{Hindawi}

Submit your manuscripts at

http://www.hindawi.com
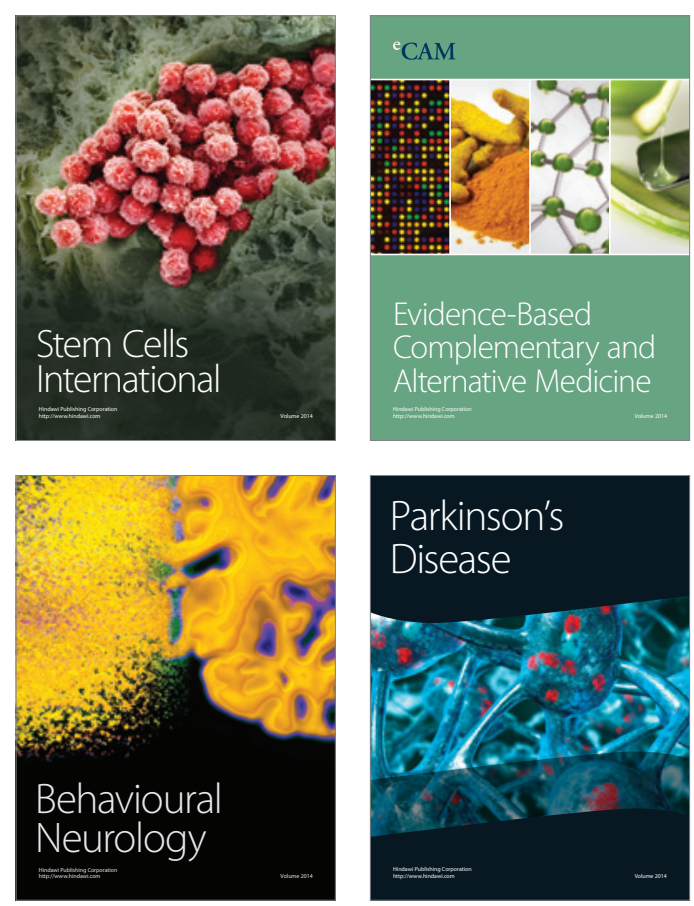

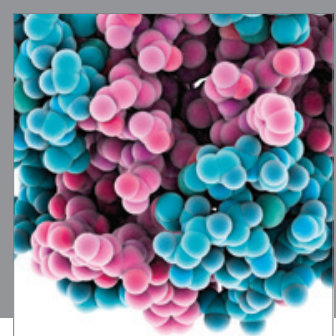

Journal of
Diabetes Research

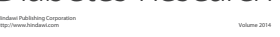

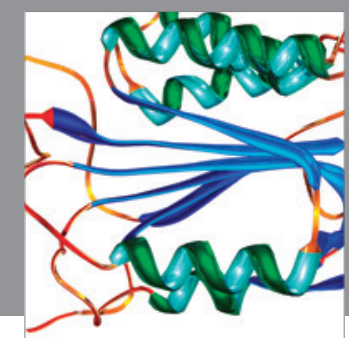

Disease Markers
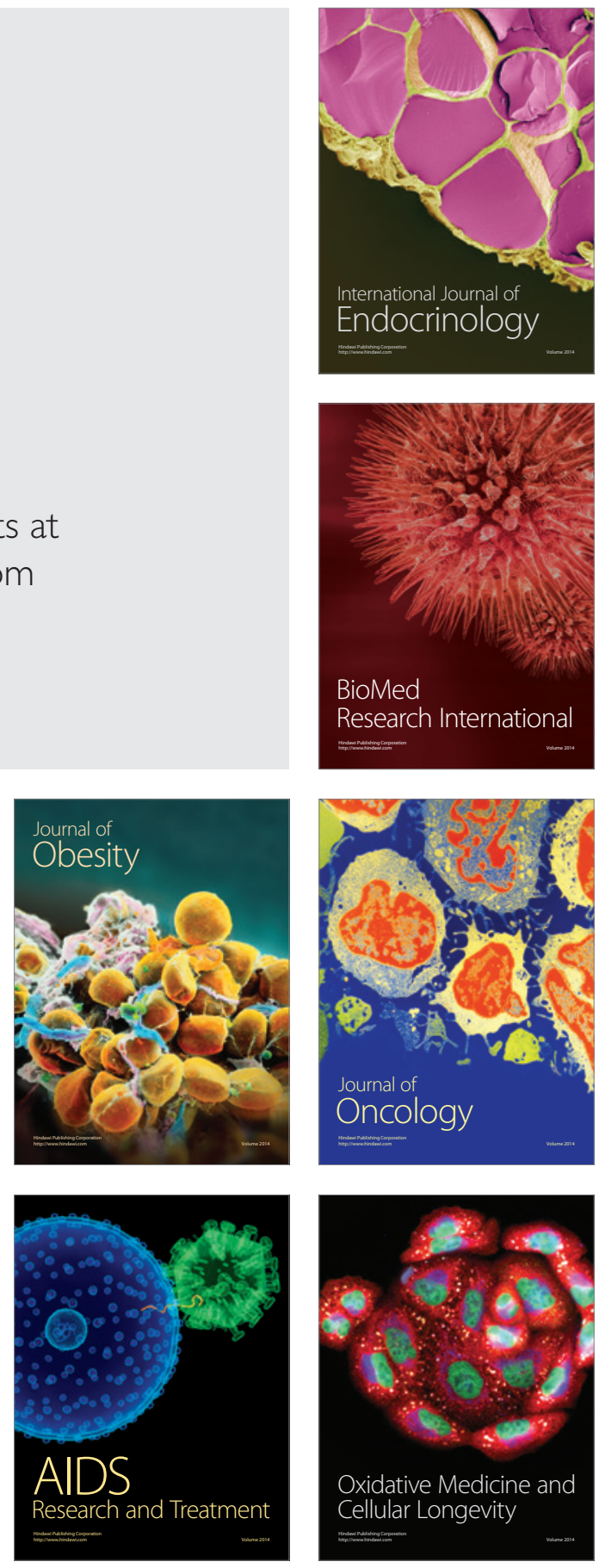